\title{
THE IMPACT OF STUDENTS' ACADEMIC LOCUS OF CONTROL AND PERCEPTION OF PROBLEM SOLVING ABILITY ON THEIR PERFORMANCE IN DESIGN PROJECTS
}

\author{
Galaleldin, Mohamed; Boudreau, Justine; Anis, Hanan \\ University of Ottawa \\ mgalalel@uottawa.ca; jboudre2@uottawa.ca; hanis@uottawa.ca
}

\begin{abstract}
The University of Ottawa has introduced new introductory engineering design courses that introduces students to engineering design through a Collaborative Project Based Learning (CPBL) environment as it is known for enhancing deep learning, motivating students to cultivate interdependence in learning, problem-solving, and creating interest and excitement in learning. Students work in teams with a client to solve an engineering problem and develop and iterate prototypes. This paper aims at understanding the impact of those two hands-on courses (Engineering Design and Introduction to Product Development and Management) on engineering students' design skills as well as the factors that impacted the students learning. The factors that are considered in this study are students' prior knowledge or experience of engineering design, students' construct locus of control, perception of problem solving ability and team dynamics. A pre-\& post-test was administered to students using a validated design process skill assessment tool to quantify students' progress during the course. Students' final prototypes were also assessed by external judges from the community to evaluate the quality of students' designs.
\end{abstract}

Keywords: Engineering Design Education; Project Based Learning; Academic Locus of Control; Problem Solving Inventory.

\section{INTRODUCTION}

Project Based Learning (PBL) is an experiential learning approach that focuses on engaging students in investigation and problem solving as students pursue a solution to non-trivial problems through research, data collection and analysis, design, ideation, communication and creating artifacts [2]. In PBL environments instructors act as facilitators who help guide the learning process through the course of the project as students work in groups to solve the problem which helps provide students with an opportunity to apply their knowledge and help connect the theory taught in the classroom to real-life experiences $[2$,
9]. The goal of situating students in a learning environment that requires them to find a solution to a problem is to allow them to construct an extensive and flexible knowledge base, develop their problem solving, life-long learning and teamwork skills, and to help students become intrinsically motivated [9].

PBL environments face several challenges such as ensuring student motivation, and finding adequate support for teachers and students. Projects have to be designed so that they ensure students' motivation with the teacher's support. Factors that impact students' motivation throughout the project include students' interest in the project, their confidence in their ability to complete the project, and whether they value the learning process more or the course's grades [2].

Barron [1] noted four principles for designing student projects in Project-Based environments to ensure that they help students become aware of the goal of their learning activities, and to ensure the acquisition of content and skills; those principles include the connection between the project activities and the conceptual knowledge the teacher wants the students to construct and develop, providing additional scaffolds that support teaching and learning processes, providing frequent opportunities for selfassessment for both instructors and students, and fostering an environment that supports active and reflective learning.

The courses understudy in this paper are (1) a first-year design course, Engineering Design, meant to teach a hands-on, team based introduction to engineering design for engineers and computer scientists. Topics include design thinking, project management, engineering design process, and prototyping, (2) The second-year design course, Introduction to Product Development and Management, is meant to teach a hands-on team based introduction to product development and management principles for engineers and computer scientists. The impact on social and economic aspects of engineering 
practice is also explored within this course. Topics include creativity and innovation, engineering project management, market evaluation and identification, engineering economics, and technology entrepreneurship.

Students learn the design skills necessary to develop products that solve significant real-world problems. They are provided with a hands-on, team-based introduction to engineering design and product development and management principles that are suitable for both engineers and computer scientists.

Both these courses follow a similar structure. The 3 hours of lecture per week is used to teach principles on design thinking, engineering design process, project management, etc. to students while the 3-hour laboratory per week is where they learn to use various tools and apply the knowledge seen in class. Engineering tools that are introduced to students during lab sessions are MS office, Arduino microcontrollers, Solidworks, 3D printing, Matlab and PCB design. Lab sessions in the first half of the semester are used to introduce students to these engineering tools, subsequently students work towards completing their assigned projects in the second half.

Students form teams based on the ir shared interest to work on a project and start working on their projects by the third week of the semester. To encourage user-centric design, the students meet with their client a minimum of three times during the semester. Client meetings occur on campus during lab sessions for the first year course, while students meet one on one with clients off campus for the second year course. During the first meeting the client explains their story and the problem they are facing to the students. The students empathize with the clients' needs to design a customized solution for them. During the second and third meetings students bring a preliminary conceptual design and first prototype to receive feedback on functionality, usability, etc. from their client. Each group of 4-5 students receives a budget of $\$ 100$ to complete their final prototype. They must make their first prototype at $\$ 0$ with reusable/recyclable materials and their next two prototypes must fit within the budget.

Examples of projects that the first-year course has worked on this semester are modules for an environmental robot that is tasked with shore cleanup and hydroponic walls for schools or structures to block pedestrians in medians. The second-year course has an accessibility theme: examples of the projects were an IR remote control for a paraplegic, a real-time subtitles app for hard of hearing and a fall detection system for elderly or disabled people.

In this study, we aimed to understand the relationship between students' characteristics and their performance and achievement in project based learning environments by identifying characteristics of successful students. Characteristics measured in this study were students' construct of locus of control, perception of problem solving ability, whether students were engaged in a previous design course and whether they have used a makerspace before. Each different personality, behaviour and previous knowledge in students will affect the way they learn in a PBL environment as well as influence their teammates.

\section{RESEARCH QUESTION}

The purpose of the present study is to investigate the relationships between students' construct of locus of control and perception of problem solving ability with their performance in a collaborative project based learning environment.

\section{METHODS}

\subsection{Participants}

Initial participants were 411 engineering students at the faculty of engineering, University of Ottawa, ON. Students had to complete the team dynamics assessment tool as part of the course-work as it was used to evaluate their contribution to the project work. Students' participation in the pre-post DSA tests, academic locus of control and problem-solving inventory questionnaires was voluntary. We performed complete case analysis by excluding cases that had missing data. The final sample size was composed of 121 engineering students (94 were male, and 27 were females) students who responded to all the instruments used in the study.

Table 1- Participants' Engineering Disciplines

\begin{tabular}{|l|c|}
\hline Engineering Discipline & $\begin{array}{c}\text { No. of } \\
\text { Participants }\end{array}$ \\
\hline Elec. Eng. & 54 \\
\hline Civil Eng. & 48 \\
\hline Mech. Eng. & 9 \\
\hline Chemical Eng. & 2 \\
\hline Computer Eng. & 5 \\
\hline Software Eng. & 2 \\
\hline Biomedical Eng. & 1 \\
\hline
\end{tabular}

\subsection{Instruments}

The study consisted of a combination of validated instruments to measure students' locus of control, problem solving skills, and team dynamics. 
3.2.1. Academic Locus of Control scale: The concept of Locus of control refers to an individual's belief about one's own control over life events. Those who feel in control for things that happen to them have an internal locus of control; while others who feel that there are forces beyond their control that determine their success or failure in a task have an external locus of control [12,4]. Research studies conducted on locus of control and academic achievement demonstrate a positive relationship between an internal locus of control and academic achievement [4].

The academic locus of control (ALC) inventory [12] is a 28 True-False questionnaire that measures students' locus of control construct at the university level. The total score range is 0 to 28; students who score between 0 and 13 have an internal locus of control, while those who score between 14 and 28 have an external locus of control. Trice [12] administered the questionnaire to 82 freshman students registered in a general psychology course. The test-retest reliability of the instrument was .92 and KR-20 internal consistency was .70. Trice found a significant negative correlation between amount of extra credit earned and scale scores. The ALC instrument has been used to understand students' construct of LoC relation with various academic behaviors, including academic performance, attendance, procrastination, and graduate school orientation [3].

3.2.2. Design Skill Assessment (DSA): The design skill Assessment (DSA) tool (Frank \& Strong, 2010) assesses students' ability to apply the design process to solve simple design problems. The tool asks students to describe the design process they would follow to solve a simple openended engineering design scenario. Student responses were evaluated against seven stages of engineering design: need identification, problem definition, preliminary design, conceptual design, detailed design, validation, and overall design process. The analytic rubric developed by Frank and Strong (2010) was modified to account for the initial step of the design thinking methodology: need identification, also students were not assessed for the use of engineering tools in their responses. Each stage was awarded a maximum of 6 points. The pre-test asked students what design process they would take to design a shopping cart, while the post-test scenario was designing a desk for the visually impaired. The tool was administered twice at the beginning of the course, and at the end. Participation was voluntary and only 121 students responded to the pre-and post-tests.

3.2.3. Problem Solving Inventory: The problem-solving inventory (PSI) $[5 ; 6]$ is a self-report problem solving ability measure that assesses an individual's perception and evaluation of his or her problem-solving ability [8]; the instrument consists of 32- six points Likert scale items that are divided between three subscales: Problem solving confidence, Approach-Avoidance style, and Personal Control. Internal consistency among the three factors ranges between $0.72 \& 0.9$ [7]. The instrument has a total score that ranges from 32 to 192 . Low scores indicate behaviors typically associated with effective problem solving, however, the PSI should not be considered as a measure of Problem solving skills. The instrument was administered through Survey Monkey page, and students were asked to respond to it during their weekly lab meetings. Students respond the statements by indicating the degree to which they agree or disagree.

3.2.4. Peer Assessment: Students were introduced to behaviors of being effective team members in the beginning of the course, and each team had to sign a contract between the members that defined the acceptable teamwork norms and expectations from each team member. Students then had to rate their peers twice during the course, the first five weeks through the semester, and the second at the last week of classes. Students rated their team members using a peer assessment and feedback tool developed by the Individual and Team Metrics Lab at the university of Calgary. The tool - which is developed based on [11] Comprehensive Assessment of Team Member Effectiveness [10] dimensions: Communication, Commitment, Knowledge, skills and abilities, standards, and keeping the team on track - invites students to rate each other on a five-point Likert scale and provide personal feedback. This feedback was used in during a team meeting mid-course as a team debrief to discuss each member's performance and areas of improvement.

\subsubsection{Project Manager Assessment:}

Project managers are second year students who have taken one or both design courses in previous semesters and have demonstrated exemplary performance and leadership in their teams. In each lab section, 1-2 project managers were assigned to help the students throughout the semester with their specific projects.

In the second-year product development class, the project managers were asked to evaluate the students at the end of the term. They were given 4 criteria: quantity of work done, quality of work done, overall value to the team and overall impression (punctuality, effective participation style, good focus, etc). Each student was graded out of 5 for each criterion, which gives a total of 20 points. Each team of two project managers discussed between themselves during the last lab session of the semester and awarded each student in their lab session points based on their participation and behavior during the semester.

\subsection{Procedure:}

Students' were asked to respond to the DSA pre-test in the first lecture of the course, and responded to the posttest in their labs two weeks before the end of the semester. We allowed students 20 minutes to complete each test. The ALC and PSI questionnaires were administered via Survey Monkey website, students responded to the 
questionnaires during their lab session one week before the end of the semester. The average time to complete the ALC questionnaire was five minutes, while it took students an average of 9 minutes to complete the PSI questionnaire. To understand the relationship between the DSA tests, ALC, PSI, and peer assessment variables we excluded students who didn't respond to any one of these three variables.

\section{RESULTS \& DISCUSSION}

Only $10(8 \%)$ students of the final sample have taken a design course before registering for this course. 18 (15\%) students have used the Makerspace before taking the course. Descriptive statistics for the ALC, PSI, and peer assessment variables are shown in Table-2 in AppendixA. Shapiro-Wilk test, Skewness, and Kurtosis values were used to determine the normality of the data. Locus of control and PSI data were normally distributed while peer assessment scores were skewed to the left.

ALC scores ranged from 3.9 to 22.1 with a mean of 12.3 $(\mathrm{SD}=3.3)$. There were no differences observed between male and female students in all variables measured. Also, we noticed no difference between students who had a prior design course and those who this course represented their first design course (refer to Table-3 in Appendix A).

Significant negative correlations were observed between ALC and PSI scores with peer assessment marks (-.24, -.24 respectively), students with low personal control - external LoC -, who had high a score on the ALC scale, received low peer evaluation with some outliers for those in teams that decided to rate all team members with a high mark on the peer assessment scale; similarly for the PSI scores the more confident a student felt about his problem solving ability the higher their peer assessment mark would be. There was also a significant positive correlation (.21) between ALC scores and PSI marks, the more a student was confident in their problem-solving effectiveness the more likely they had an internal locus of control.

We also found that there is no correlation between the pre-post design skill assessment tests and ALC \& PSI marks. We think this is due to the fact that the DSA instrument measures students' knowledge and familiarity with applying the design process, and can't predict students' self-beliefs nor achievement in a collaborative project environment.

For the project manager marks and peer assessment study table 4 presents the descriptive statistics for the secondyear product development class. A strong significant positive correlation between project manager marks and peer assessment marks were noted for the second-year product development course sample (.54). The relationship indicates that students peer assessment correlated with project managers rating. The correlation between the PM marks and the peer assessment marks indicate that PMs assessment is a reliable measure for evaluating students' contribution in a collaborative project based learning environment.

\section{FUTURE RESEARCH}

The current study was limited to exploring the relationship between students' LoC construct, and their beliefs in their problem-solving capabilities with their performance in a team based environment. This article was limited by time since the project marks, and final courses' grades were not finalized by the conference deadline.

Also, for future research we are planning to administer studies that assess students design and problem-solving skills prior to taking a PBL design course and assessing it's relationship with students' achievement.

\section{Acknowledgements}

This work is supported by the Natural Sciences and Engineering Research Council of Canada (Chair in Entrepreneurial Engineering Design).

\section{References}

[1] B. J. S. Barron, D. L. Schwartz, N. J. Vye, A. Moore, A. Petrosino, L. Zech, and J. D. Bransford, "Doing With Understanding: Lessons From Research on Problem- and Project-Based Learning," J. Learn. Sci., vol. 7, no. 3-4, pp. 271-311, 1998.

[2] P. C. Blumenfeld, E. Soloway, R. W. Marx, J. S. Krajcik, M. Guzdial, and A. Palincsar, "Motivating Project-Based Learning: Sustaining the Doing, Supporting the Learning," Educ. Psychol., vol. 26, no. 3-4, pp. 369-398, 1991.

[3] N. A. Curtis and A. D. Trice, "A Revision of the Academic Locus of Control Scale for College Students," Percept. Mot. Skills, vol. 116, no. 3, pp. 817-829, Jun. 2013.

[4] M. J. Findley and H. M. Cooper, "Locus of control and academic achievement: A literature review.," J. Pers. Soc. Psychol., vol. 44, no. 2, pp. 419-427, 1983.

[5] P. P. Heppner and C. H. Petersen, "Problem Solving Inventory," J. Couns. Psychol., vol. 29, pp. 66-75, 1982.

[6] P. P. Heppner and C. H. Petersen, "Problem Solving Inventory," J. Couns. Psychol., vol. 29, pp. 66-75, 1982. 
[7] P. P. Heppner, A. H. Baumgardner, L. M. Larson, and R. E. Petty, "The Utility of Problem-solving Training that Emphasises Self-management Principles," Couns. Psychol. Q., vol. 1, no. 2-3, pp. 129-143, 1988.

[8] P. P. Heppner and C. E. Baker, "Applications of the Problem Solving Inventory,” Meas. Eval. Couns. Dev., pp. 229-241, 1997.

[9] C. E. Hmelo-Silver, "Problem-based learning: What and how do students learn?," Educational Psychology Review, vol. 16, no. 3. pp. 235-266, 2004.

[10] T. O’Neill, S. Park, N. L. Larson, A. Deacon, G. Hoffart, B. Brennan, M. Eggermont, and W. Rosehart, "Peer Ratings and Intentions to Change: Adopting the CATME to Explore Outcomes of Peer Ratings: American Society for Engineering Education," in ASEE Annual Conference and Exposition, Conference Proceedings. , 2015.

[11] M. W. Ohland, M. L. Loughry, D. J. Woehr, L. G. Bullard, R. M. Felder, C. J. Finelli, R. A. Layton, H. R. Pomeranz, and D. G. Schmucker, "The Comprehensive Assessment of Team Member Effectiveness: Development of a Behaviorally Anchored Rating Scale for Self- and Peer Evaluation," Acad. Manag. Learn. Educ., vol. 11, no. 4, pp. 609-630, Dec. 2012.

[12] A. D. Trice, "An Academic Locus of Control Scale for College Students," Percept. Mot. Skills, vol. 61, pp. 1043-1046, Dec. 1985. 


\section{APPENDIX A: TABLES}

Table 2 - Mean, standard deviation, range and correlation values

\begin{tabular}{|c|c|c|c|c|c|c|c|c|c|c|c|c|c|c|c|}
\hline \multirow[b]{2}{*}{ Variable } & \multirow[b]{2}{*}{$\mathrm{N}$} & \multirow[b]{2}{*}{$M$} & \multirow[b]{2}{*}{ SD } & \multirow[b]{2}{*}{ Range } & \multicolumn{4}{|c|}{ Males (n=94) } & \multicolumn{4}{|c|}{ Females $(n=27)$} & \multicolumn{3}{|c|}{ Pearson Correlation } \\
\hline & & & & & $\mathrm{N}$ & M & SD & Range & $\mathrm{N}$ & M & SD & Range & 1 & 2 & 3 \\
\hline ALC & 121 & 12 & 3 & $3.9-22.1$ & 94 & 12 & 3 & $\begin{array}{l}3.9- \\
22.1\end{array}$ & 27 & 12 & 11 & $7.0-17.9$ & - & & \\
\hline PSI & 121 & 121 & 10 & $\begin{array}{l}86.4- \\
159.4\end{array}$ & 94 & 120 & 11 & $\begin{array}{l}86.4- \\
159.4\end{array}$ & 27 & 123 & 9 & $\begin{array}{c}105.6- \\
144.0\end{array}$ & $.221^{*}$ & - & \\
\hline $\begin{array}{l}\text { Peer } \\
\text { Ass }\end{array}$ & 97 & 4 & 5 & $2.6-5.0$ & 77 & 5 & 1 & $\begin{array}{l}2.6- \\
5.0\end{array}$ & 20 & 5 & 0 & $3.4-5.0$ & $\begin{array}{c}- \\
0.237 \\
*\end{array}$ & $\begin{array}{c}- \\
0.239 \\
*\end{array}$ & - \\
\hline \multicolumn{5}{|l|}{ Skewness } & & & & & & & & & 0.364 & 0.377 & -1.77 \\
\hline \multicolumn{5}{|l|}{ Kurtosis } & & & & & & & & & 0.138 & 2.068 & 3.21 \\
\hline
\end{tabular}

$*(\mathrm{P}<0.05)$

Table 3 - Mean, Standard Deviation, and Range comparison between students who had prior design experience and those who ddin't

\begin{tabular}{|c|c|c|c|c|c|c|c|c|}
\hline \multirow[b]{2}{*}{ Variable } & \multicolumn{4}{|c|}{ Registered for a previous design course $(\mathrm{n}=18)$} & \multicolumn{4}{|c|}{$\begin{array}{l}\text { Didn't have any previous design experience } \\
(\mathrm{n}=103)\end{array}$} \\
\hline & $\mathrm{N}$ & $\mathrm{M}$ & SD & Range & $\mathrm{N}$ & $M$ & SD & Range \\
\hline ALC & 18 & 11.88 & 2.67 & $7.0-16.0$ & 103 & 11.90 & 3.38 & $3.9-22.1$ \\
\hline PSI & 18 & 120 & 6.85 & $109.4-138.2$ & 103 & 122.57 & 10.97 & $86.4-159.4$ \\
\hline $\begin{array}{l}\text { Peer } \\
\text { Assessment }\end{array}$ & 16 & 4.76 & 0.23 & $4.3-5.0$ & 81 & 4.55 & 0.57 & $2.6-5.0$ \\
\hline
\end{tabular}

Table 4 - Mean, standard deviation, range and correlation values for Pm marks and Peer Assessment study

\begin{tabular}{|c|c|c|c|c|c|c|c|c|c|c|c|}
\hline & & & & $\mathrm{Mr}$ & es $(n=94$ & & & ales $(\mathrm{n}=$ & & & \\
\hline Variable & $\mathrm{N}$ & Median & Range & $\mathrm{N}$ & Median & Range & $\mathrm{N}$ & Median & Range & 1 & 2 \\
\hline $\begin{array}{l}\text { Peer } \\
\text { Assessment }\end{array}$ & 54 & 95 & $20-100$ & 48 & 4.58 & $1.4-5$ & 6 & 4.35 & $3.53-5$ & - & \\
\hline PM Marks & 54 & 4.55 & $1.4-5.0$ & 48 & 95 & $20-100$ & 6 & 90 & $60-100$ & $.54 *$ & - \\
\hline
\end{tabular}

$*(\mathrm{P}<0.05)$ 